\title{
3D Model of Pavement Distress Based on Road Gradient Using Unmanned Aerial Vehicle
}

\author{
Yackob Astor ${ }^{1}$, Retno Utami ${ }^{1 *}$, Sarah Nabilah Winata ${ }^{1}$, \\ F A Rahman ${ }^{1}$, F A Gustaman ${ }^{1}$, M R Firdaus ${ }^{1}$
}

${ }^{1}$ Civil Engineering Department, Politeknik Negeri Bandung, Indonesia

*Corresponding author. Email: retnoutami@polban.ac.id

\begin{abstract}
The implementation of UAVs in Indonesia on road infrastructure projects still widely used at the planning stage of new road routes and the supervision stage to determine the progress of the work. Meanwhile, at the post-work monitoring stage, the UAV is only used to identify and inventory the pavement distress in determining the type of damage, not followed by the further pavement assessment. This study aims to determine the type of damage and the dimensions (area and depth) of the damage and determine the level of pavement distress. Data acquisition was carried out by taking direct photos using a drone of some damage to the road segment based on different road gradients in the study location, which was a $1 \%-6 \%$ slope. Photos taken from the drone are processed according to the rules of photogrammetry to produce an orthophoto as a 3D model. Furthermore, identification and inventory of types of pavement distress are carried out, as well as calculating the dimensions (area and depth) of pavement distress on photo maps. A minimum value difference of $0.3 \mathrm{~cm}$ to $3 \mathrm{~cm}$ is obtained from the calculation of the dimensions of the pavement distress in the model against the results of measurements in the field. The level of precision of the dimensions of the pavement distress in the model is not affected by the gradient of the road, meaning that the $3 \mathrm{D}$ model does not make the value of the depth of the pothole on a high road gradient more precise.
\end{abstract}

\section{Keywords: Pavement Distress, road infrastructure, Road Gradient, UAV}

\section{INTRODUCTION}

Unmanned Aerial Vehicle (UAV) unmanned flying aircraft or commonly referred to as drones is a relatively new and very interesting technology. Several aspects of the development of this UAV technology are based on a performance like a manned aircraft. The flying performance of unmanned aircraft that is often used as a measure and discussed by actors and fans of this technology is the ability to fly (long distance), long-endurance, the ability to fly automatically (autonomous flying), take-off and landing capabilities. These capabilities become benchmarks and technological achievements also innovations of unmanned aircraft, which include aspects of propulsion, avionics, and aerodynamics [1]. Technological developments have also made drones to be widely applied for civilian needs, especially in the fields of business, industry, and logistics, various services such as forest fire fighting, exploration of mining materials, mapping of agricultural areas, mapping of industrial areas, and supervision of infrastructure including roads [2]. The advantage of using drones lies in the ability to fly at an altitude of $<20 \mathrm{~m}$ above ground level so that they can photograph real-time objects in the field very well to produce large-scale map products in 2D and 3D.

The implementation of UAVs in Indonesia on road infrastructure projects is currently still widely used at the planning stage of new road routes and the stage of monitoring the implementation of work to determine the progress of the work. Meanwhile, at the post-work monitoring stage, the UAV is only used to identify and inventory the pavement distress to determine the type of damage, not yet proceed to the road condition assessment stage. On the other hand, road condition assessment is important in road monitoring and maintenance. Several overseas studies have optimized drones as a traffic and transportation management tool [3], it is also very useful for various maintenance, planning, and operational functions such as accidents, surveys, security inspections, 
construction data collection, and monitoring of road conditions and congestion. highway [4]. Hart (2011) conducted a study using UAVs for monitoring road conditions and concluded that UAVs are very well observed and can help transportation agencies for inventory and surveys of road conditions and road maintenance [5].

Zhang (2008) photographed the damage to an unpaved road using a UAV. The results of aerial photos displayed in 2D are able to show good road damage by interpreting aerial photos through shape, pattern, color, and image classification. This research has not discussed much technically about the process and the results of 3D aerial photography. However, he mentioned the importance of 3D models to identify road damage, because only through a $3 \mathrm{D}$ view can the slope of the road be obtained: slopes/inclines (vertical geometrics), curve (horizontal geometrics), and potholes [6]. In a subsequent study, Zhang (2012) built a 3D model through the reconstruction of aerial photographs using a UAV to assess the damage to unpaved roads. The resulting 3D model shows that road damage can be interpreted from the irregular shape and texture of the ground surface, as well as the different heights of the ground surface which are displayed through different colors. In this study, there are still some errors in the interpretation of the results caused by the shadow factor that was taken during the shooting, and the camera's spatial resolution is too low, causing the texture of the ground surface in the 3D model to be less visible.[7]

The photo of the pavement distress was carried out by Leonardi (2018) using a drone from a height of $25 \mathrm{~m}$ so that a good picture was obtained. Identification of pavement distress in aerial photos is done using Matlab through black and white color interpretation. The black color shows cracks and potholes in the road. It was concluded that the drone method reduces economic costs and time to get accurate results [8]. Iradaf (2020) uses UAVs to identify and classify pavement distress, as well as calculate the extent of pavement distress. Obtained 6 types of pavement distress visual interpretation results with an accuracy value of $96.36 \%$. This study concludes that UAVs can be relied upon for inspection of types of distress on the flexible pavement (asphalt), inexpensive, flexible, easy to operate and produce high-resolution images [9]. Tan (2019) builds a 3D model from aerial photography using a UAV to identify the type of pavement distress, calculates the dimensions of the pavement distress area and the depth/height of the road, and detects road unevenness automatically using the Region Growing Algorithm. Comparison between the results of calculations on the 3D model with measurements in the field obtained the accuracy at the centimeter level. UAV is an excellent and promising tool for road work.[10]
Thus far, pavement distress assessment in Indonesia is still carried out manually by surveying in the field using the Pavement Conditions Index (PCI) or Surface Distress Index (SDI) method based on the visual road condition survey which identified the type of distress, severity, and quantity. These methods require some time to collect field data and observe pavement distress in which creates problems, such as safety in medium-tohigh traffic volume and disrupts traffic flow on relatively narrow roads. Those problems happened at the study site, Cikalong-Cipeundeuy road in Cikalongwetan District, West Bandung Regency, West Java. The Cikalong-Cipeundeuy road, based on government administration, is categorized as a district road and class IIIA road with a road width of $5 \mathrm{~m}$. The CikalongCipeundeuy road is located at an altitude of $467 \mathrm{~m}$ to $703 \mathrm{~m}$ from the mean sea level and has a slope of $0-8 \%$ (Figure 1).

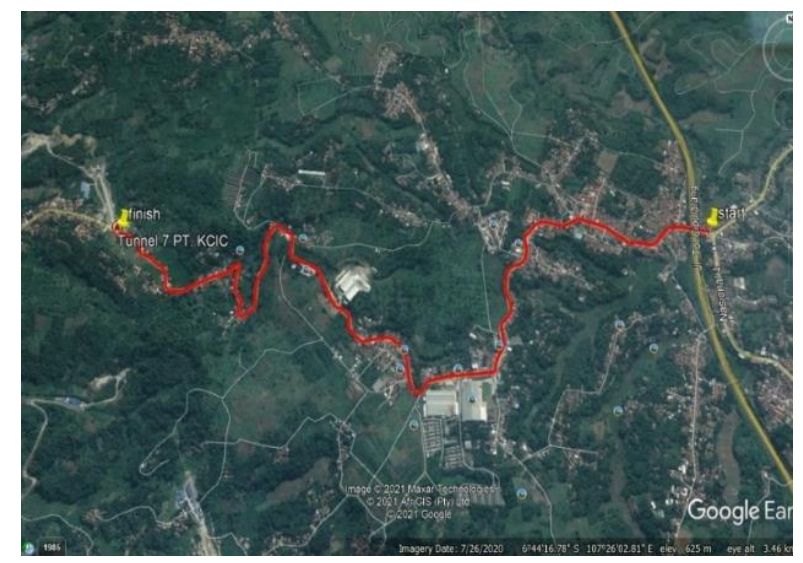

Figure 1. Tracks of Cikalong-Cipeundeuy road (Google Earth, 2021).

Since 2018, West Bandung Regency has been an area affected by the construction of the Jakarta Bandung Fast Train (KCJB) National Strategic Project by PT Kereta Cepat Indonesia China (KCIC). The area that experienced the most serious impact from the construction project was Kanagasari Village, Cikalongwetan District. The Walini Tunnel was built along $608 \mathrm{~m}$ with a diameter of $14.3 \mathrm{~m}$ which became the first tunnel that was successfully penetrated in this KCJB Project. The impact of the tunnel construction is very visible on the pavement distress of the CikalongCipeundeuy road because the road is access for heavy vehicles to the project (Figure 2). 


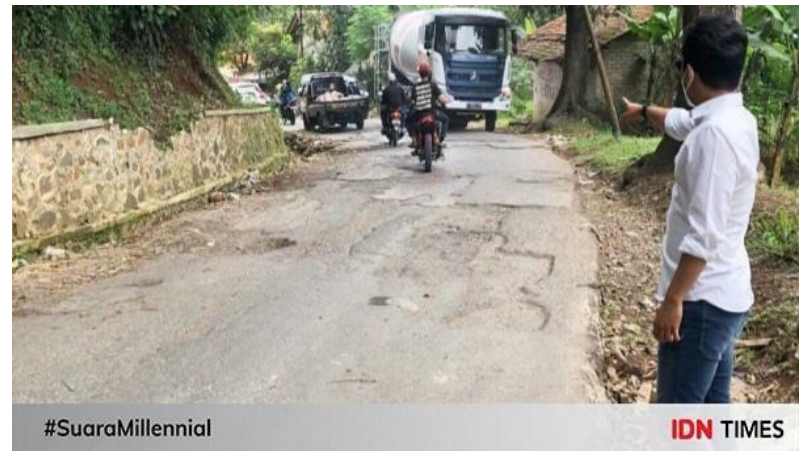

Figure 2. Damaged road due to heavy loading KCIC Project (IDN Times Jabar, 2021).

The pavement distress on the Cikalong-Cipeundeuy road has been very severe and has caused many traffic accidents such as vehicles falling due to the collapsed road causing casualties. The road condition is currently experiencing severe damage along the $4.5 \mathrm{~km}$ which varied from light, moderate, to severe damage. Pavement distress in Cikalong-Cipeundeuy road can be seen in Figure 3.
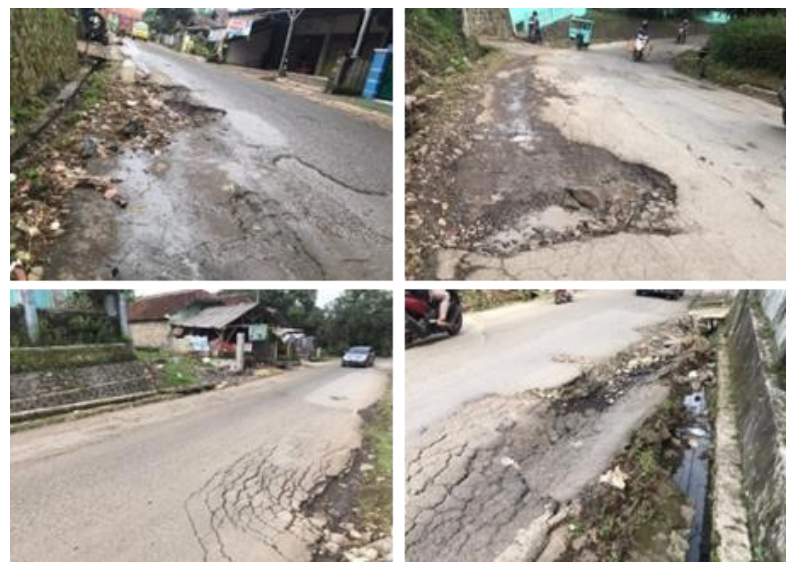

Figure 3. Pavement distresses in Cikalong-Cipeundeuy road.

In this study, the pavement distress on CikalongCipeundeuy road photographed using a drone with a minimum height according to the height of the buildings and trees around the road. The photos are processed according to photogrammetry rules to produce a $3 \mathrm{D}$ model for primary data that is used to identify the type of damage, take an inventory of the amount of damage, and calculate the dimensions of the damage. Validation is done by comparing the results of pavement distress surveys in the field based on different road gradients, in this study divided into 2 classes, slope $<3 \%$ and $>3 \%$. This is done to determine the effect of the slope of the photographed road on the accuracy of the dimensions of pavement distress, in this case, the depth of distress.

\section{METHODS}

The drone used in this study is the Phantom 4 Pro, which has a flight time of up to 30 minutes and has a Two-Frequency Signal Control $2.4 \& 5 \mathrm{Ghz}$ with a range of $7 \mathrm{~km}$. The drone was flown at a height of $15 \mathrm{~m}$ and an overlap of $60 \%$ to photograph a $4 \mathrm{~km}$ road with a total of 21 Ground Control Points (GCP) (Figure 4). The shooting was done on $2 \mathrm{x}$ projects by dividing $4 \mathrm{~km}$ into 2 parts (Figure 5). GCP observations were carried out using a Leica 900 Geodetic GPS using the Real-Time Kinematic (RTK) 1 set method. The GCP coordinates are shown in Table 1.



Figure 4. Research object and GCP positions.

From the results of shooting using drones, 2388 photos were obtained. Furthermore, photo processing is carried out using Agisoft Metashape Professional software. Starting from the Align photo stage, which is reconstructing photos from aerial photos based on flight paths and predetermined conditions such as area boundaries and $60 \%$ overlap so that a sequential and orderly overlay of photos is obtained (Figure 5). In this study location, the next step is to input GCP coordinates on each aerial photo. The results of the bundle adjustment process obtained a total RMSE of $2 \mathrm{~cm}$ (Fig.5a) and $2 \mathrm{~mm}$ (Figure.5b). This RMSE difference is caused at location $5 \mathrm{~b}$ there is a difference in ground level and more trees which can affect the accuracy of GCP observations in the field. The number of GCPs at location 5a is 9 points less than at location $5 b$. 
Table 1. GCP coordinates

\begin{tabular}{|l|c|c|c|}
\hline \multicolumn{1}{|c|}{ GCP } & $X(\mathrm{~m})$ & $\mathrm{Y}(\mathrm{m})$ & $\mathrm{Z}(\mathrm{m})$ \\
\hline Base Fix & 768523.2804 & 9254348.644 & 678.995 \\
\hline GCP 1 FIX & 769451.9704 & 9254898.007 & 635.033 \\
\hline GCP 2 FIX & 769276.3354 & 9254866.149 & 641.694 \\
\hline GCP 3 FIX & 769059.8736 & 9254878.578 & 653.184 \\
\hline GCP 4 FIX & 768905.4343 & 9254946.438 & 659.328 \\
\hline GCP 5 FIX & 768672.3103 & 9254888.788 & 667.781 \\
\hline GCP 6 FIX & 768652.4129 & 9254795.07 & 668.723 \\
\hline GCP 7 FIX & 768537.6981 & 9254509.273 & 676.626 \\
\hline GCP 8 FIX & 768508.075 & 9254362.866 & 678.993 \\
\hline GCP 9 FIX & 768378.9548 & 9254319.105 & 674.966 \\
\hline GCP 10 FIX & 768164.7687 & 9254237.289 & 665.603 \\
\hline GCP 11 FIX & 767988.5762 & 9254468.586 & 650.407 \\
\hline GCP 12 FIX & 767819.0405 & 9254580.317 & 638.556 \\
\hline GCP 12 A FIX & 767661.2741 & 9254780.447 & 630.567 \\
\hline GCP 13 FIX & 767402.0729 & 9254570.933 & 593.661 \\
\hline GCP 14 FIX & 767344.2391 & 9254694.545 & 580.742 \\
\hline GCP 15 FIX & 767257.4359 & 9254746.859 & 565.516 \\
\hline GCP 16 FIX & 767022.436 & 9254708.622 & 554.198 \\
\hline GCP 17 FIX & 766982.6854 & 9254802.191 & 546.727 \\
\hline GCP 18 FIX & 766886.6169 & 9254876.733 & 542.381 \\
\hline GCP 19 FIX & 766786.2981 & 9254957.6 & 540.334 \\
\hline GCP 20 FIX & 766726.425 & 9254977.007 & 537.886 \\
\hline
\end{tabular}

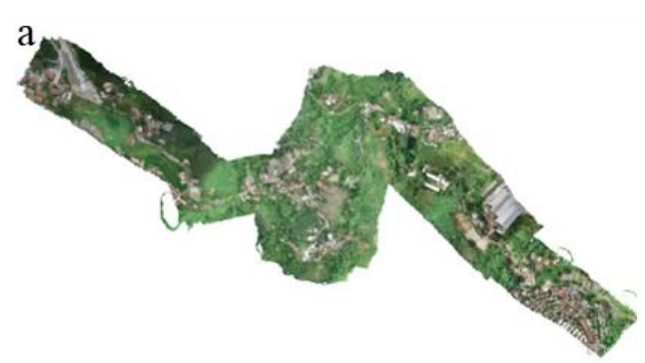

b

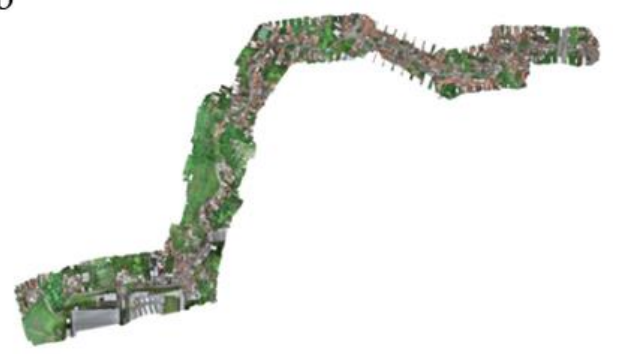

Figure 5. Aerial photo align.
The next process is Build Dense Cloud. This process aims to obtain a 3D model based on the classification of points and the level of density of the points used. The higher the quality of the photos used, the closer and more points will be produced. In this study, the process with Medium quality was chosen. After the Dense Cloud Build process is complete, it is continued with the 3D Mesh Build process to display a 3D model visualization based on the overlay of point classification and density resulting from the Dense Cloud process. From the results of the Build 3D Mesh, a Digital Elevation Model (DEM) can be made as shown in Figure 6.

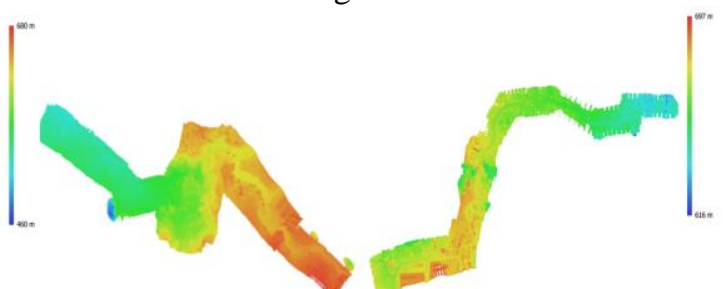

Figure 6. Digital Elevation Model. 
The last stage is the manufacture of orthophoto as a model, by combining the results of Align aerial photos that have a minimum RMSE with DEM so that a 3D aerial photo is obtained which has one scale (even for fields of varying heights) and still presents the actual situation in the field. An orthophoto is planimetrically correct, so it can be considered as a map or more accurately called an orthophoto map, so that distance, angle, position, area, and height/depth measurements can be made directly on the orthophoto (3D model).

\section{RESULTS AND DISCUSSION}

The following is a 3D model produced in this study shown from the top view (Figure 7a) and side view (Figure $7 b)$.

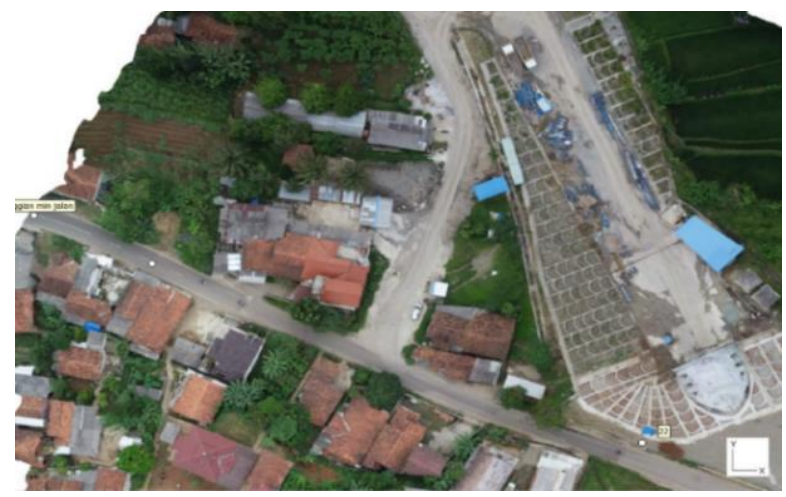

Figure 7a. 3D Model (top view).

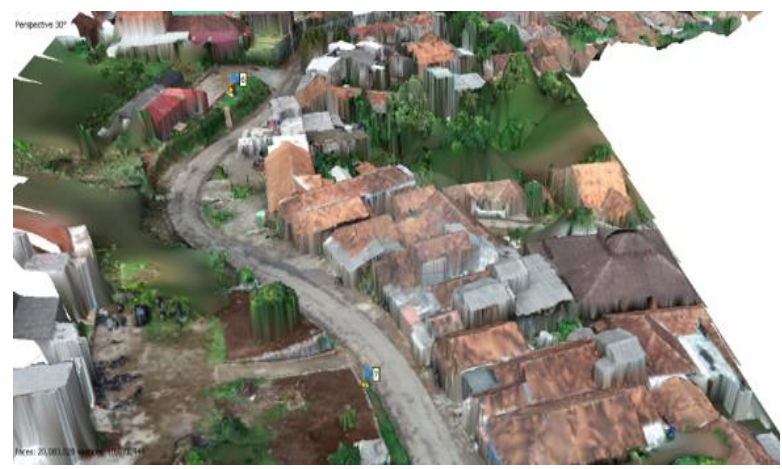

Figure 7b. 3D Model (side view).

In the 3D model, interpretation and identification of the types of pavement distress are carried out. Furthermore, a comparison of the appearance of the type of damage in the $3 \mathrm{D}$ model with the conditions in the field is carried out. Figure 8 shows that the 3D model can show the condition of pavement distress clearly so it is very easy to identify the types of pavement distress that exist in the research location.
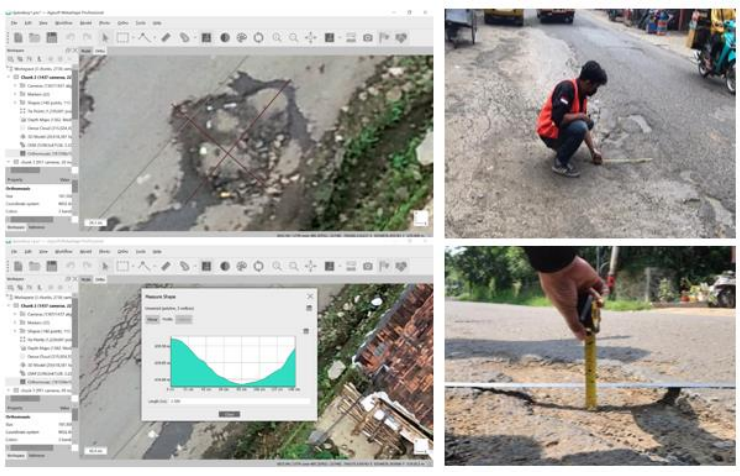

Figure 9. Calculation of pavement distress dimensions on model (left) and real conditions in the field (right).

Table 2 showed that the drone can inform the value of the dimensions of pavement distress close to the results of direct measurements in the field. Planimetrically $(\mathrm{X}, \mathrm{Y})$ resulted in a difference of values at least $0.3 \mathrm{~cm}$ and a maximum of $3 \mathrm{~cm}$. In this study, the size of pavement distress did not affect the precision of the dimension value obtained, as shown in Table 2 that pothole no. 6 , which has a width of $142.3 \mathrm{~cm}$ in the model, turns out to be only $0.3 \mathrm{~cm}$ different from the width of measurements in the field. Unlike pothole no. 5 which has a width of $30 \mathrm{~cm}$ in the model has a value difference of $2.56 \mathrm{~cm}$ to the measurement results in the field.

Similar to the size of the dimensions of distress, it was not seen that the difference in slope gradient affected the planimetric value of the damage dimension and the depth (h) of pavement distress, in this case, potholes. The 3D model does not always make the depth pothole value more precise at high gradient paths. In Table 2 it can be seen that Pothole no. 2 has a depth value of $2.067 \mathrm{~cm}$ in the model, only $0.93 \mathrm{~cm}$ different from the depth measurement results in the field on a road gradient of $4.83 \%$. This value is smaller than Pothole no. 7 which has a depth value of $9.1 \mathrm{~cm}$ in the model and a difference of $1.1 \mathrm{~cm}$ to the depth value measured in the field on a road gradient of $6.56 \%$. Vice versa, some data from this study also showed that the depth Pothole value at a lower road gradient does not always have a better precision value than a higher road gradient.

The precision of depth in pothole from the model against the results of field measurements can be low when the pothole is flooded with water. In Table 2 no. 4 the difference in depth values can reach $3.7 \mathrm{~cm}$, this is because the software in the model detects the water puddle height as the pothole soil surface. Therefore, aerial photography should not be taken after it rains even the day before, or it can be ensured that there are no puddles on the road. 
Table 2. Types of pavement distress and dimensions comparisons on model and real conditions measure based on road gradient.

\begin{tabular}{|c|c|c|c|c|c|}
\hline No & Type of distress in 3D Model & $\begin{array}{l}\text { Road Gra- } \\
\text { dient (\%) }\end{array}$ & $\begin{array}{l}\text { Dimensions on } \\
\text { 3D model }(\mathrm{cm})\end{array}$ & $\begin{array}{l}\text { Dimensions on } \\
\text { real condition } \\
\text { measure }(\mathrm{cm})\end{array}$ & $\begin{array}{l}\text { Differences in di- } \\
\text { mensions }(\mathrm{cm})\end{array}$ \\
\hline 1 & & $1,4 \%$ & $\begin{array}{l}\text { Length }=120,5 \\
\text { Width }=94,4\end{array}$ & $\begin{array}{l}\text { Length }=120 \\
\text { Width }=94\end{array}$ & $\begin{array}{l}0,5 \\
0,4\end{array}$ \\
\hline 2 & & $2,9 \%$ & $\begin{array}{l}\text { Length }=696,8 \\
\text { Width }=163\end{array}$ & $\begin{array}{l}\text { Length }=699 \\
\text { Width }=160\end{array}$ & $\begin{array}{c}2,2 \\
3\end{array}$ \\
\hline 3 & & $3,8 \%$ & $\begin{array}{l}\text { Length }=65,88 \\
\text { Width }=58,76\end{array}$ & $\begin{array}{l}\text { Length }=67 \\
\text { Width }=60\end{array}$ & $\begin{array}{l}1,12 \\
1,24\end{array}$ \\
\hline 4 & & $4,08 \%$ & $\begin{array}{l}\text { Length }=60,5 \\
\text { Width }=37,5 \\
\text { Depth }=1.3 \\
\text { (water puddle) }\end{array}$ & $\begin{array}{l}\text { Length }=60 \\
\text { Width }=37 \\
\text { Depth }=5\end{array}$ & $\begin{array}{l}0,5 \\
0,5 \\
3,7\end{array}$ \\
\hline 5 & & $4,83 \%$ & $\begin{array}{l}\text { Length }=64,19 \\
\text { Width }=32,56 \\
\text { Depth }=2,067\end{array}$ & $\begin{array}{l}\text { Length }=67 \\
\text { Width }=30 \\
\text { Depth }=3\end{array}$ & $\begin{array}{l}2,81 \\
2,56 \\
0,93\end{array}$ \\
\hline 6 & & $6,027 \%$ & $\begin{array}{l}\text { Length }=174,7 \\
\text { Width }=142,3 \\
\text { Depth }=8,9 \\
\text { (water puddle) }\end{array}$ & $\begin{array}{l}\text { Length }=174 \\
\text { Width }=142 \\
\text { Depth }=10\end{array}$ & $\begin{array}{l}0,7 \\
0,3 \\
1,1\end{array}$ \\
\hline 7 & & $6,56 \%$ & $\begin{array}{l}\text { Length }=67 \\
\text { Width }=64,08 \\
\text { Depth }=9,1\end{array}$ & $\begin{array}{l}\text { Length }=69 \\
\text { Width }=67 \\
\text { Depth }=8\end{array}$ & $\begin{array}{c}2 \\
2,92 \\
1,1\end{array}$ \\
\hline
\end{tabular}




\section{CONCLUSION}

Based on the discussion above, it is concluded that drones can be used as a tool that can be used to identify types of pavement distress. Moreover, the drone output in the form of orthophoto can be used as a 3D model to calculate the dimensions of the pavement distress planimetrically $(\mathrm{X}, \mathrm{Y})$ and the depth $(\mathrm{h})$ of pavement distress with a precision of $0.3 \mathrm{~cm}$ to $3 \mathrm{~cm}$ to the value of the measurement results in the field. The precision level of pavement distress dimensions from the $3 \mathrm{~d}$ model did not affect by types of distress or gradient of the road. Also, the 3D model does not give more dimension precision in the depth of potholes in high road gradients.

For further research, it is necessary to take aerial photos of pavement distress at higher road gradients such as road slopes $>10 \%$ and $>25 \%$. Thereby it can be analyzed the effect of the existing DEM in the 3D model on the level of precision of the distress depth on hilly and mountain roads. In addition, to get the best resolution from the resulting 3D model, a drone and computer with high specifications are needed and choose the highest level option at each stage of the data processing process using the software.

The benefit of this research in the field of engineering is to contribute to the application of UAV as an efficient method for assessing pavement distress as a reference for the government in carrying out road repair and maintenance efforts. While in the scientific field, this research contributes to the potential development of the Pavement Condition Index (PCI) or Surface Distress Index (SDI) method using UAV.

\section{ACKNOWLEDGMENT}

This research is an applied research funded by the Bandung State Polytechnic PNBN for the 2021 fiscal year.

\section{REFERENCES}

[1] Lembaga Penerbangan dan Antariksa Nasional/ LAPAN. (2021). Lapan Surveillance UAV 02 (LSU

https://www.lapan.go.id/page/teknologi/1/lapansurveillance-uav-02-lsu-02.

[2] Suroso, I. (2016). Peran Drone (UAV) buatan STTKD dalam Dunia Penerbangan. https://puskkpa.lapan.go.id/

[3] Gebre, ED. (2008). Remotely Piloted Vehicles/UAV Surveillance for Transportation Management and Security. Intellegent Transportation System Institute, University of Minnesota.

[4] Mc Cormack, Edward. (2009). Exploring Transpor- tation Application of Small Unmanned Aircraft. Institute of Transportation, ITE Journal, Vol.12, pp.32-36.

[5] Hart, W.S., Gharaibeh, NG. (2011). Use of Micro UAV in Roadside Condition Surveys. Proceeding of 1st Congress of the Transportation and Development Institute of ASCE, pp.80-92.

[6] Chunsun Zhang. (2008). An UAV Based Photogrammetric Mapping System for Road Condition Assessment. The International Archives of the Photogrammetry, Remote Sensing and Spatial Information Science. Vol.XXXVII. Part.B5, Beijing, 2008.

[7] Chunsun Zhang. (2012). An Unmanned Aerial Vehicle Based Imaging System for 3D Measurement of Unpaved Road Surface Distresses. Computer Aided Civil and Infrastructure Engineering, No.27 p.118-129. https://doi.org/10.1111/j.14678667.2011.00727.x

[8] Giovanni Leonardi, Vincenzo Barrile, Rocco Palamara, Federica Suraci, and Gabriele Candela. (2018). Road Degradation Survey Through Images by Drone. Springer International Publishing AG, part of Springer Nature 2019. https://doi.org/10.1007/978-3-319-92102-0_24

[9] Iradaf Mandaya dan Harintaka. (2020). Pemanfaatan Teknologi UAV untuk Identifikasi dan Klasifikasi Jenis kerusakan Jalan. Jurnal Rekayasan Sipil, Vol.14 No.3. ISSN: 1978-5658.

[10] Yumin Tan and Yunxin Li. (2019). UAV Photogrammetry Based 3D Road Distress Detection. International Journal of Geoinformation, No.8, 409. https://doi.org/10.3390/ijgi8090409 